\title{
The Buccal Lid Approach for Removal of Impacted Mandibular Molars- When, How and Why?
}

\author{
Fares Kablan', Victoria Yaffe ${ }^{1}$, Imad Abu El-Naaj ${ }^{2}$ \\ ${ }^{1}$ Department of Oral and Maxillofacial Surgery, Baruch Padeh Medical Center, Poriya, Israel \\ ${ }^{2}$ Department of Oral and Maxillofacial Surgery, Baruch Padeh Medical Center, Affiliated to the Faculty of Medicine of Bar-Ilan \\ University in the Galilee, Poriya, Israel \\ Email: vikayaffe@gmail.com
}

How to cite this paper: Kablan, F., Yaffe, V. and Abu El-Naaj, I. (2017) The Buccal Lid Approach for Removal of Impacted Mandibular Molars-When, How and Why? Open Journal of Stomatology, 7, 81-90. http://dx.doi.org/10.4236/ojst.2017.71004

Received: October 3, 2016

Accepted: January 10, 2017

Published: January 13, 2017

Copyright $\odot 2017$ by authors and Scientific Research Publishing Inc. This work is licensed under the Creative Commons Attribution International License (CC BY 4.0).

http://creativecommons.org/licenses/by/4.0/

\begin{abstract}
Background: The surgical removal of impacted mandibular molars represents one of the most prevalent procedures carried out by the oral and maxillofacial surgeon. Despite its prevalence, unusual impaction location of mandibular molars necessitates alternative extraction approaches. One of the methods described for extraction of deeply impacted molars is the bony lid approach which was first presented for surgical endodontic treatment of mandibular molars. The aim of this study was to evaluate the outcome of the bony lid approach in extracting mandibular molars. In addition, critical clinical key points, new aspects while performing this procedure, indications and contraindications are discussed. Materials and Methods: 9 patients were treated with the bony lid technique. A retrospective analysis of medical charts was conducted to evaluate the results of surgery. Results: The operative technique described in the article was successfully carried out in 12 cases of impacted mandibular molars. No incidence of permanent sensory deficit was recorded. In one patient, an infection mandated the removal of the bony lids. In all other cases the healing process was uneventful. Conclusion: The bony lid technique has many advantages over alternative extraction methods and should be considered as a treatment option in cases of critical proximity between an impacted tooth and the inferior alveolar nerve.
\end{abstract}

\section{Keywords}

Buccal Lid, Mandibular Molars, Extraction

\section{Introduction}

Impacted mandibular third molars are a common diagnosis with a reported fre- 
quency of $20 \%$ to $30 \%$ [1]. Conversely, impaction of mandibular first and second molars is an infrequently encountered finding with a described prevalence of less than $0.01 \%$ [2] [3] and $1.36 \%$ [4], respectively.

Surgical removal, especially of impacted mandibular third molars, is among the most common procedures carried out by oral and maxillofacial surgeons.

Management of deeply impacted molars, unusual impaction locations and intimate proximity to the inferior alveolar nerve (IAN) mandates the surgeon to neglect the conventional approach. In such cases, alternative techniques have been described, and include: coronectomy [5], sagittal split osteotomy (SSO) and extraoral approaches, each with its own advantages and complications [6].

The most often debated complication after removal of impacted mandibular molars is the neurosensory deficit of the IAN and Lingual nerves (LN). Historically, IAN and LN injuries were reported with an incidence of $0.26 \%-8.4 \%$ and $0.1 \%-22 \%$, respectively. In a recent study conducted by Cheung et al. examining 4338 lower third molar extractions, $0.35 \%$ developed IAN deficit and $0.69 \%$ developed LN deficit [7]. Other serious complications following extraction of impacted mandibular molars include mandibular fracture, damage to adjacent teeth and displacement of teeth or tooth fragments into adjutant spaces [6]. Surgical removal of impacted molars is also associated with expected outcomes, such as: pain, swelling, reduction in mouth opening capacity [8], odynophagia and dysphagia [9] [10].

An additional alternative technique that can be utilized for the extraction of deeply impacted molars is conducted via the removal of the lateral cortical plate as described by Alling [11]. The nomenclatures for this procedure varied among clinicians and referred to as: bone lid, buccal mandibular osteotomy, buccal window and buccal corticotomy. Various indications for its use have been described in the literature including: apical root resection of lower molars [12], repair of inferior alveolar nerve [13] and removal of impacted mandibular molars [11] or implants [14]. The advantages of this procedure include an intraoral approach that provides excellent surgical access with direct vision to the impacted tooth, enables bone saving and minimizes the injury to adjacent teeth and tissues [15].

Despite its many advantages, "buccal corticotomy" or "buccal window" is not considered as a common practice when dealing with deeply impacted molars.

The aim of the current study is to support the use of buccal window osteotomy and present new aspects while performing this procedure through the clinical experience gained in our department. Furthermore, the surgical procedure, indications and contraindications are discussed.

\section{Materials and Methods}

A retrospective analysis of 12 lower molar extractions carried out via the buccal window approach in 9 patients (Table 1) in the Oral and Maxillofacial Surgery outpatient clinic of the Baruch Peda medical center from 2008 to 2014 was conducted. The study was approved by the Helsinki ethical committee of the Baruch Peda medical center. 
Table 1. Description of cases using the bony lid technique.

\begin{tabular}{|c|c|c|c|c|}
\hline $\begin{array}{l}\text { Patient } \\
\text { number }\end{array}$ & Age & $\begin{array}{l}\text { Mandibular molar } \\
\text { extracted }\end{array}$ & Gender & Procedure regarding bone lid \\
\hline \multirow{3}{*}{1} & & $3^{\text {rd }}$ Right & \multirow{3}{*}{$\mathrm{F}$} & Re-positioned to original site, without fixation \\
\hline & 16 & & & \\
\hline & & $3^{\text {rd }}$ Left & & Re-positioned to original site, without fixation \\
\hline 2 & 12 & $1^{\text {st }}$ Left & $\mathrm{F}$ & $\begin{array}{l}\text { Re-positioned to original site and fixated } \\
\text { with non-absorbable micro-plates }\end{array}$ \\
\hline 3 & 15 & $2^{\text {nd }}$ Left & M & $\begin{array}{l}\text { Re-positioned to original site and fixated } \\
\text { with non-absorbable micro-plates }\end{array}$ \\
\hline \multirow{3}{*}{4} & \multirow{3}{*}{21} & $3^{\text {rd }}$ Left & \multirow{3}{*}{$\mathrm{M}$} & $\begin{array}{l}\text { Re-positioned to original site and fixated } \\
\text { with non-absorbable micro-plates }\end{array}$ \\
\hline & & & & \\
\hline & & $3^{\text {rd }}$ Right & & $\begin{array}{l}\text { Re-positioned to original site and fixated } \\
\text { with non-absorbable micro-plates }\end{array}$ \\
\hline \multirow{3}{*}{5} & & $3^{\text {rd }}$ Left & \multirow{3}{*}{$\mathrm{F}$} & $\begin{array}{l}\text { Re-positioned to original site and fixated } \\
\text { with non-absorbable micro-plates }\end{array}$ \\
\hline & 27 & & & \\
\hline & & $3^{\text {rd }}$ Right & & $\begin{array}{l}\text { Re-positioned to original site and fixated } \\
\text { with non-absorbable micro-plates }\end{array}$ \\
\hline 6 & 27 & $2^{\text {nd }}$ Right & $\mathrm{F}$ & $\begin{array}{l}\text { Re-positioned to original site and fixated } \\
\text { with non-absorbable micro-plates }\end{array}$ \\
\hline 7 & 59 & $4^{\text {th }}$ Left & M & Bone lid was used for anterior augmentation \\
\hline 8 & 75 & $2^{\text {nd }}$ Left & M & $\begin{array}{l}\text { Bone lid wasn't re positioned due to enlarge } \\
\text { buccal flange of denture }\end{array}$ \\
\hline 9 & 24 & $3^{\text {rd }}$ Right & M & $\begin{array}{l}\text { Re-positioned to original site and fixated } \\
\text { with non-absorbable micro-plates }\end{array}$ \\
\hline
\end{tabular}

All 9 patients (mean age of 30 years old, 4 female and 5 male patients) were diagnosed with impacted lower molars with/without adjacent pathology that required extraction. All patients were evaluated with panoramic radiographs and cone beam computerized tomography (CBCT, i.e. dental CT) prior to the surgery (Figure 1(a), Figure 1(b), Figure 2(a), Figure 3(a)). The impacted teeth were classified based on the classification proposed by Abu-El Naaj et al. (Table 1) [6].

Patients were excluded if they failed to appear at follow-up. 9 patients (a total of 12 buccal window osteotomies) met the criteria, and their charts were reviewed to evaluate the results of surgery.

Follow up of the surgical site included clinical examination twice at the first month after the operation, and every three months. Panoramic radiograph was performed immediately post-op, after 3 months, 6 months, one year, and thereafter once a year.

\section{Surgical Procedure}

Apart from one patient (patient No. 9 who underwent the procedure under local anesthesia), all operations were performed under general anesthesia. A full thickness mucoperiosteal flap extending to the ramus with an anterior releasing 
incision was reflected. The bony lid was outlined with a small round bur at the superior portion (Figure $1(\mathrm{c})$ ). The additional three cuts, posterior, anterior and inferior were performed with disc micro saw (Frius microsaw, Friadent). Then, the buccal bone window was easily elevated with straight and curved osteotomes. The removal of the bone window provided a wide access and a direct visualization of the tooth (Figure 1(d)). The tooth was gently separated and removed. The surgical site was directly inspected and evaluated with gentle irrigation. In 8 cases the buccal window was repositioned and fixed with one of two micro plates (Figure 1(e), Figure 2(b)). In one case the bilateral buccal windows were repositioned without fixation, but with mechanical retention. In another case, the buccal window was used for augmentation of the anterior mandibular ridge. The
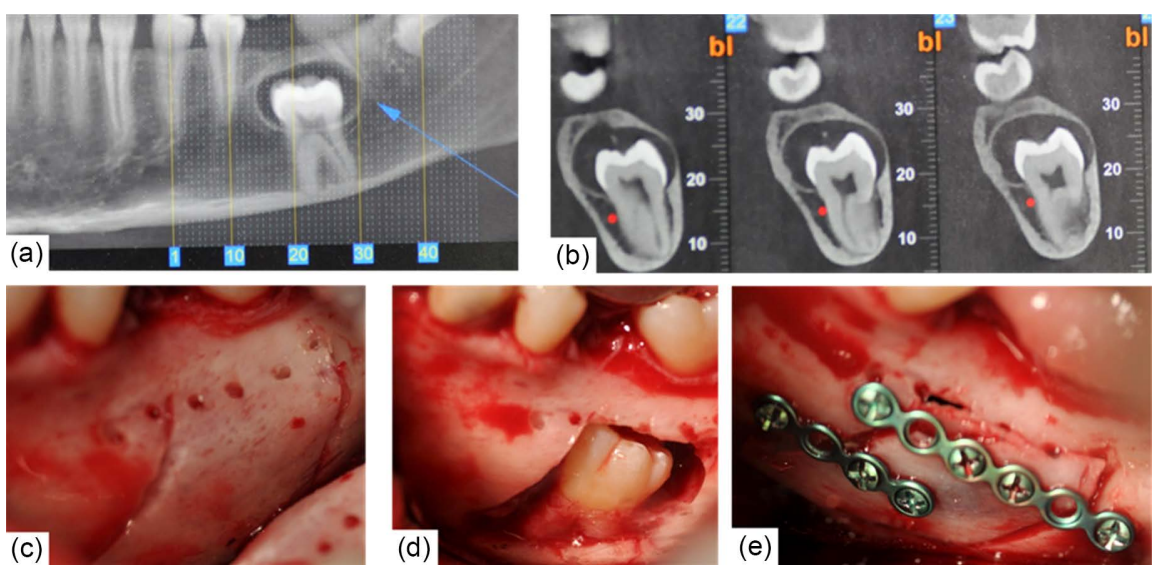

Figure 1. (a) Patient No. 2 presented with a deeply impacted left mandibular first molar with a radiolucent lesion surrounding its crown, CBCT; (b) Sagittal sections of CBCT exhibiting lingual position of IAN (red dot); (c) Outlining of the bony lid; (d) An excellent direct view of the tooth (after removal of involved lesion); (e) Repositioning and fixation of buccal lid with mini-plates.
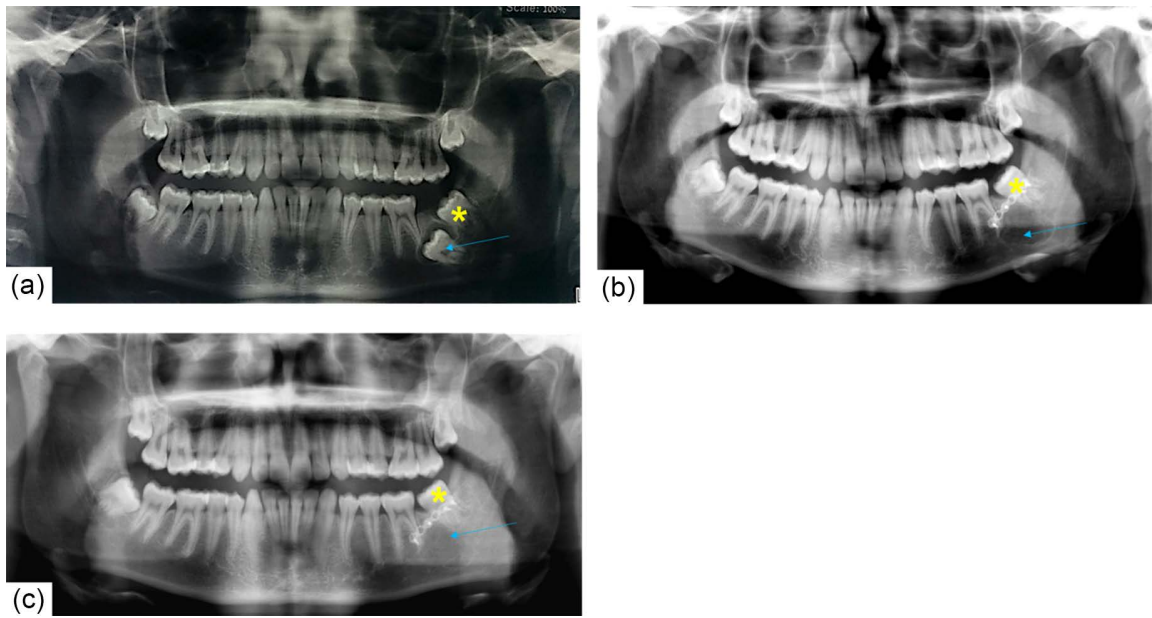

Figure 2. Bone remodeling following buccal lid osteotomy. Preoperative panoramic view exhibiting a deeply impacted second mandibular molar (blue arrow) (a) 5 months post op (b) and 9 months post op (c). Note the bone filling following the procedure (blue arrow). Also note the spontaneous eruption of the third molar (yellow asterisk) indicating no disturbance caused by the micro plate. 

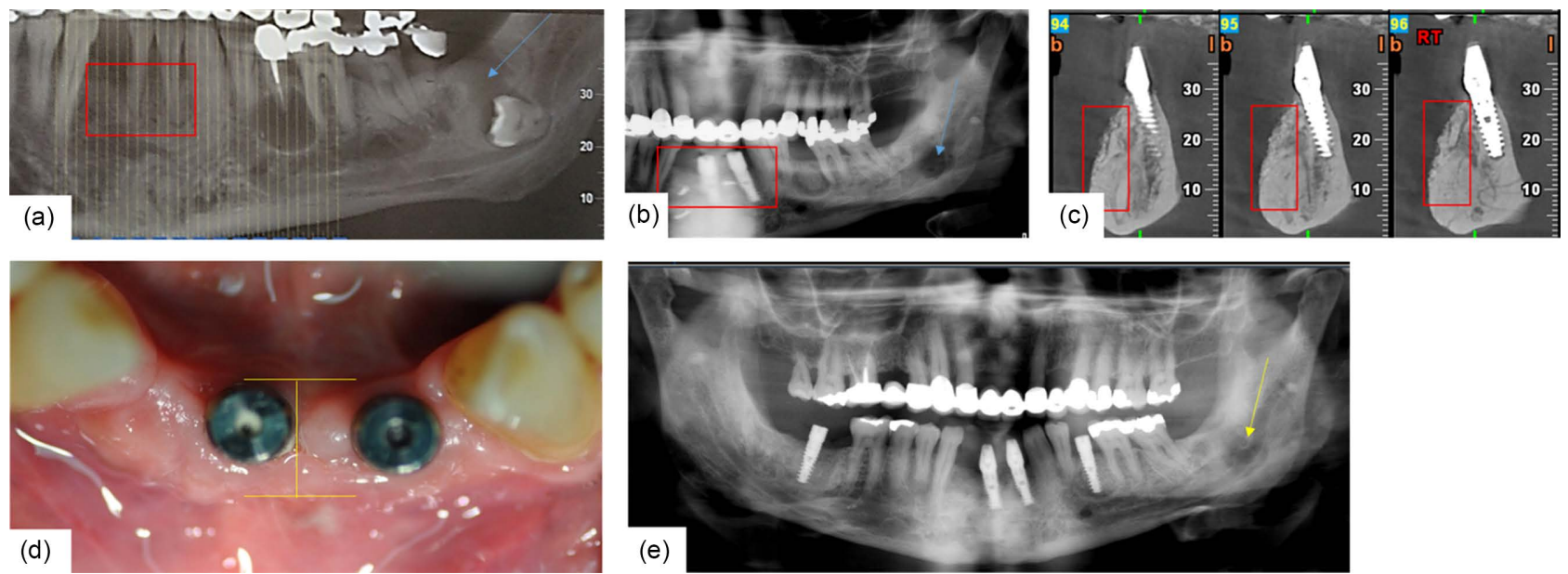

Figure 3. Using the buccal lid for augmentation. (a) A 59 year old male presented with a deeply impacted fourth mandibular molar with an adjacent pathology (blue arrow) and increased mobility of left mandibular incisors due to reduced alveolar support, red rectangle. (b) Panoramic view, 1 month after extractions of incisors and fourth mandibular molar, augmentation using the buccal lid and placement of 2 dental implants, red rectangle. Post op follow up presented (c) abundant buccal bone in sagittal CBCT sections, red rectangles and (d) in clinical intraoral examination, yellow bar. In (e) note the remarkable bone healing 11 month post op (yellow arrow) as opposed to the 1 month post op (blue arrow in b).

last case was an edentulous mandible with complete dental prosthesis that interfered with the repositioning of the bone lid.

In all cases the mucoperiosteal flap was sutured with $4 / 0$ coated Vicryl.

The postoperative instructions included: oral administration of antibiotics for 1 postoperative week (amoxicillin 1.5 gram/day), soft diet for six weeks and meticulous oral hygiene including mouth rinse twice a day with chlorhexidine $0.2 \%$ solution for two weeks.

\section{Results}

A total of 12 buccal window osteotomies were performed. Post-operative complication in form of infection occurred in only one case (11\%). Of note, the site of infection was diagnosed in the case where the bony lids weren't fixated but rather placed in their position. Infection demanded the removal of the bony lids through a second stage surgery. In all the remaining cases the healing process was uneventful. Good bone healing on panoramic radiographs was observed on average after 6 months (Figure 2, Figure 3). In addition, the contour and the bone level of the surgical site were preserved.

Although in two of our patients a temporary post-operative lower lip hypoesthesia was noted, it resolved completely after 2 months. No incidence of permanent sensory deficit was recorded.

Using the buccal lid for augmentation revealed as a double success-the impacted molar was extracted with the outmost minimal risk to the IAN and the augmented bone enabled immediate placement of dental implants (Figure 3).

\section{Discussion}

Deep and unusual impaction of first, second and third molars are not uncom- 
mon. In our group of patients the bone lid technique was indicated for unusual impactions of 7 third mandibular molars, 1 first mandibular molar, 3 second mandibular molar and 1 unique case of a $4^{\text {th }}$ mandibular molar.

In cases of deeply impacted molars, the removal of the impacted tooth via the conventional approach (i.e. direct osteotomy of the overlying dentoalveolar process) can result in incomplete extraction, IAN injury, LN injury and damage to adjacent teeth. To improve access while using the conventional approach, massive bone removal should be performed which can lead to another serious complication in the form of iatrogenic mandibular fracture. An additional disadvantage of the massive bone removal is the formation of periodontal defects distal to the mandibular second molar after wisdom tooth extractions [16]. Performing the buccal osteotomy as described enables to bypass this drawback.

SSO and extraoral approaches can be alternative approaches when dealing with deep impactions, but both necessitate hospitalization. Although SSO is a predictable way to remove unusual impacted mandibular molars [6], it is a major surgical procedure with undesired morbidity and complications. The major disadvantages of the extraoral approaches are the possible injury to facial nerve and the cosmetic sequel of skin scar. SSO and external approaches are of use when removing teeth that are impacted or displaced highly in the mandibular ramus, at the lower border of the mandible (i.e. type III, according to the third molar classification proposed by Abu-El Naaj et al. [6]) or in extreme lingual positions. In two cases of our sample the SSO was a surgical option that was discussed but finally revoked.

In cases of impacted mandibular molars with root apices in close proximity to the mandibular canal, 2 additional treatment options are available. These include coronectomy [5] and orthodontic forced extrusion [17] [18]. Despite the fact that both of the procedures may relieve the potential for neural damage, high patient compliance is necessary for optimal treatment outcome. Moreover, forced extrusion is time consuming, can take up to 12 weeks for appropriate extrusion and necessitates follow up visits every 2 - 3 weeks to monitor movement and replace the elastic chain [18].

While the oral and maxillofacial literature offers many publications addressing the postoperative morbidity following removal of mandibular molars, few studies also examined the postoperative healing period and its influence on the quality of life [19] [20]. In a prospective study of 201 patients who underwent mandibular third-molar surgery, dysphagia was one of the main reasons associated with inability to work following the procedure [19]. Dysphagia develops following surgical removal of mandibular molars due to the need for soft tissue flap elevation and bone reduction at the lingual side of the tooth. This in turn results in a postoperative swelling of the lingual tissues. As with other complications [8], we reckon that the overall incidence and severity of dysphagia is associated directly with the depth of impaction. With the buccal lid approach the lingual tissues remain intact. Sequentially, this eliminates the postoperative dysphagia and the associated discomfort. 
The excessive lingual surgical exposure during the conventional surgery also increases the possibility of LN injury. Every surgical incision located too far lingually or penetrating the lingual cortex with a surgical bur may injure the LN [21]. Moreover, once lingual nerve is damaged, amongst other complaints, the patient will report of drooling and changes while swallowing [21]. Thus, another important advantage of the buccal window approach which derives from the noninvolvement of the lingual tissues is the exclusion of the possibility of LN injury.

As mentioned, IAN injuries are a major concern while performing extractions of impacted mandibular teeth, with its following morbidities [7]. These increase while dealing with unusual and deep impactions of mandibular molars due to great proximity between the tooth and the IAN. In the present study, all patients presented with mandibular molars that were classified as type II (according to the third molar classification proposed by Abu-El Naaj et al. [6]) with the IAN located on the lingual surface of the tooth (Figure 1(b), Figure 4). The locations of the impactions were not accessible with the conventional approach. The removal of buccal bone window provided superb access to the impacted tooth with excellent visibility of the entire surgical site, safe separation and removal of the teeth without nerve injury (as evident by the non-existents of permanent nerve injury) and without applying excessive forces over the bone.

One relative contraindication of the bone lid approach may be a buccal position of the IAN in relation to an impacted tooth (Figure 5). This scenario may be managed through the buccal window while performing nerve lateralization away from the tooth and repositioning of the nerve after tooth removal.

Regarding the surgical procedure, some important aspects must be emphasized. The occlusal/superior line of the bone window was located at the superior cortex or at the lateral buccal mandibular plate, its exact position determined by the depth of the impaction. The superior line was outlined using a low speed hand piece with a small round bur. This enables a clear-cut separation of the
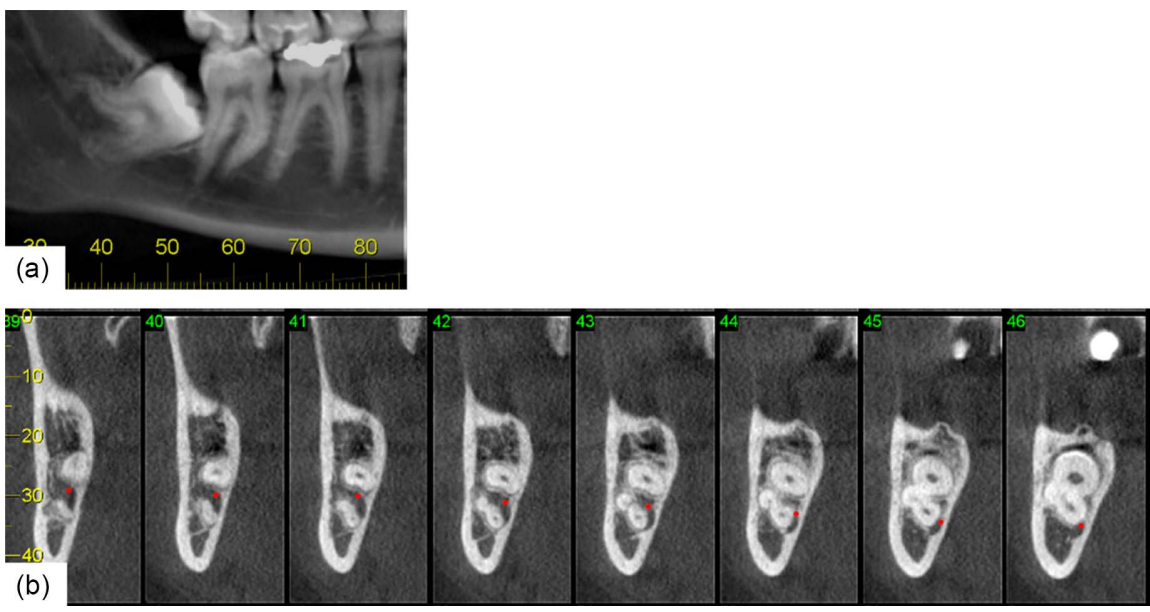

Figure 4. (a) CBCT panoramic view exhibiting an additional case treated via the buccal lid approach due to lingual position of IAN as can be viewed in (b) sagittal sections of $\mathrm{CBCT}$, red dot indicating IAN. 


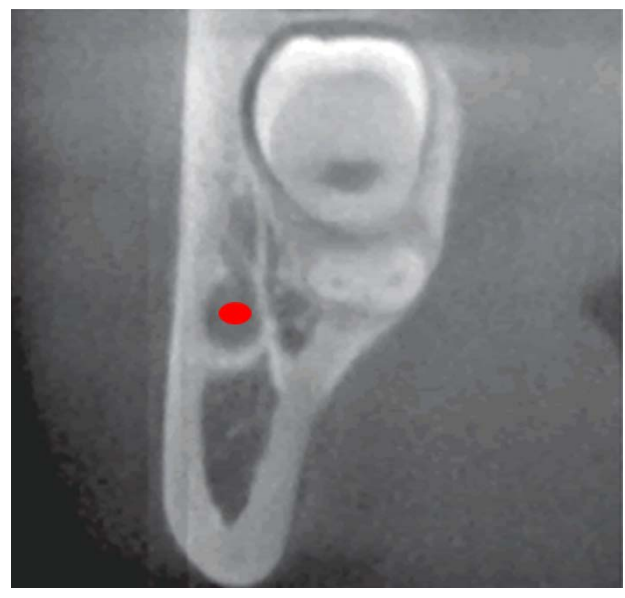

Figure 5. Buccal position of the IAN in relation to an impacted tooth. Red dot indicating IAN.

bone lid at the adjacent teeth level which in turn leads to preservation of bone contour at the surgical site.

For the posterior, anterior and inferior borders of the buccal window osteotomy Frius microsaw, was used. Due to its sharpness and known width (3 millimeters) the use of this instrument facilitates performing sharp and thin cut lines with predictable and controllable depth of the osteotomy. The precise osteotomy also improves the accurate sitting of the bone lid during its repositioning.

In one case, that was our first experience with the bone lid approach, right and left mandibular third molars were accessed and removed. The bone lids were repositioned without fixation, due to excellent intraoperative fitting and stability. In the post-operative follow up, the patient presented with a pus discharging fistula which mandated the removal of both bone lids due to infection. We hypothesized that the bone lids became loosened during bone remodeling, leading to their instability and infection. Subsequently, the following cases were managed with fixation of the bone lids even where an adequate primary fitting and stability was observed. In all remaining cases, no further infections were observed.

In addition to unusual impaction locations of mandibular molars that necessitates alternative extraction approaches, factors as age and body mass index can increase the difficulty of extractions [22]. In our experience with the buccal bone window approach, despite advanced age of two patients (59 and 75 years old) the procedure itself and postoperative healing were uneventful. This may be an important additional advantage of this approach.

\section{Conclusions}

In cases of deeply impacted mandibular molars, the surgeon is obligated to consider the variety of treatment options and select the most suitable technique which will enable a fast and effective treatment with the lowest morbidity. The choice of the technique lies primarily on the position of the tooth and the proximity to the IAN. Therefore, most impacted mandibular molars which are classi- 
fied as type I (according to the third molar classification proposed by Abu-El Naaj et al. [6]) can be managed successfully via the conventional approach. However, when dealing with impacted teeth classified as IIa or IIb, especially those in which the nerve lies lingual to the tooth, the bony lid approach should be considered as a validated treatment option.

The bony lid technique has many advantages over alternative extraction methods. It provides excellent access to the impacted tooth. Thus, even with great proximity of the crown/root to the inferior alveolar canal, the nerve itself can be separated under direct visualization and therefore protected. In addition, the buccal window approach minimizes the periodontal risk to adjacent teeth and since there is no need for lingual flap elevation the LN remains protected outside of the surgical field and the possibility of dysphagia is eliminated.

\section{Conflicts of Interest}

The authors declare that they have no conflicts of interest in the research.

\section{References}

[1] Andreasen, J.O., Petersen, J.K. and Laskin, D.M. (1997) Textbook and Color Atlas of Tooth Impactions-Diagnosis, Treatment and Prevention. Mosby Year Book, St Louis.

[2] Grover, P.S. and Lorton, L. (1985) The Incidence of Unerupted Permanent Teeth and Related Clinical Cases. Oral Surgery, Oral Medicine, Oral Pathology and Oral Radiology, 59, 420-425. https://doi.org/10.1016/0030-4220(85)90070-2

[3] Valmaseda-Castellón, E., De-la-Rosa-Gay, C. and Gay-Escoda, C. (1999) Eruption Disturbances of the First and Second Permanent Molars: Results of Treatment in 43 Cases. American Journal of Orthodontics and Dentofacial Orthopedics, 116, 651658. https://doi.org/10.1016/S0889-5406(99)70200-3

[4] Cassetta, M., Altieri, F., Di Mambro, A., Galluccio, G. and Barbato, E. (2013) Impaction of Permanent Mandibular Second Molar: A Retrospective Study. Medicina Oral Patologia Oral y Cirugia Bucal, 18, e564-e568. https://doi.org/10.4317/medoral.18869

[5] Knutsson, K., Lysell, L. and Rohlin, M. (1989) Postoperative Status after Partial Removal of Mandibular Third Molar. Swedish Dental Journal, 13, 15.

[6] Abu-El Naaj, I., Braun, R., Leiser, Y. and Peled, M. (2010) Surgical Approach to Impacted Mandibular Third Molars-Operative Classification. Journal of Oral and Maxillofacial Surgery, 68, 628-633. https://doi.org/10.1016/j.joms.2009.07.072

[7] Cheung, L.K., Leung, Y.Y., Chow, L.K., Wong, M.C., Chan, E.K. and Fok, Y.H. (2010) Incidence of Neurosensory Deficits and Recovery after Lower Third Molar Surgery: A Prospective Clinical Study of 4338 Cases. International Journal of Oral and Maxillofacial Surgery, 39, 320-326. https://doi.org/10.1016/j.ijom.2009.11.010

[8] Ness, G.M. (2011) Impacted Teeth, Peterson's Principles of oral and Maxillofacial Surgery. 3rd Edition, Vol. I, Chapter 5, 107.

[9] Vaiman, M., Nahlieli, O. and Eliav, E. (2006) Oynophagia in Patients after Dental Extraction: Surface Electromyography Study. Head \& Face Medicine, 2, 34 https://doi.org/10.1186/1746-160X-2-34

[10] Vaiman, M. and Nahlieli, O. (2009) Oral vs. Pharyngeal Dysphagia: Surface Electromyography Randomized Study. BMC Ear, Nose and Throat Disorders, 9, 3. 
https://doi.org/10.1186/1472-6815-9-3

[11] Alling, R., Alling, C.C. III (1993) Removal of Impacted Teeth and Lesions from Unusual Locations. Oral and Maxillofacial Surgery Clinics of North America, 5, 111119.

[12] Khoury, F. and Hensher, R. (1987) The Bony Lid Approach for the Apical Root Resection of Lower Molars. International Journal of Oral and Maxillofacial Surgery, 16, 166-170. https://doi.org/10.1016/S0901-5027(87)80125-X

[13] Miloro, M. (1995) Surgical Access for Inferior Alveolar Nerve Repair. Journal of Oral and Maxillofacial Surgery, 53, 1224-1225. https://doi.org/10.1016/0278-2391(95)90642-8

[14] Jung, S.R., Bashutski, J.D. and Linebaugh, M.L. (2013) Application of Modified Bony Lid Technique to Remove or Replace Compromised Implants: Case Series. Implant Dentistry, 22, 206-211. https://doi.org/10.1097/ID.0b013e31828edced

[15] Khoury, F. (2013) The Bony Lid Approach in Pre-Implant and Implant Surgery: A Prospective Study. European Journal of Oral Implantology, 6, 375-384.

[16] Kan, K.W., Liu, J.K., Lo, E.C., Corbet, E.F. and Leung, W.K. (2002) Residual Periodontal Defects Distal to the Mandibular Second Molar 6 - 36 Months after Impacted Third Molar Extraction. Journal of Clinical Periodontology, 29, 1004-1011. https://doi.org/10.1034/j.1600-051X.2002.291105.x

[17] Bonetti, G.A., Parenti, S.I. and Checchi, L. (2008) Orthodontic Extraction of Mandibular Third Molar to Avoid Nerve Injury and Promote Periodontal Healing. Journal of Clinical Periodontology, 35, 719-723. https://doi.org/10.1111/j.1600-051X.2008.01286.x

[18] Flanagan, D. (2012) Forced Extrusion for Removal of Impacted Third Molars Close to the Mandibular Canal. Revista Española de Cirugía Oral y Maxilofacial, 34, 25 30. https://doi.org/10.1016/j.maxilo.2011.10.003

[19] Berge, T.I. (1997) Inability to Work after Surgical Removal of Mandibular Third Molars. Acta Odontologica Scandinavica, 55, 64-69. https://doi.org/10.3109/00016359709091944

[20] Colorado-Bonnin, M., Valmaseda-Castellón, E., Berini-Aytés, L. and Gay-Escoda, C. (2006) Quality of Life Following Lower Third Molar Removal. International Journal of Oral and Maxillofacial Surgery, 35, 343-347. https://doi.org/10.1016/j.ijom.2005.08.008

[21] Ziccardi, V.B. and Zuniga, J.R. (2007) Nerve Injuries after Third Molar Removal. Oral and Maxillofacial Surgery Clinics of North America, 19, 105-115. https://doi.org/10.1016/j.coms.2006.11.005

[22] Gbotolorun, O.M., Arotiba, G.T. and Ladeinde, A.L. (2007) Assessment of Factors Associated with Surgical Difficulty in Impacted Mandibular Third Molar Extraction. Journal of Oral and Maxillofacial Surgery, 65, 1977-1983.

https://doi.org/10.1016/j.joms.2006.11.030 
Submit or recommend next manuscript to SCIRP and we will provide best service for you:

Accepting pre-submission inquiries through Email, Facebook, LinkedIn, Twitter, etc. A wide selection of journals (inclusive of 9 subjects, more than 200 journals)

Providing 24-hour high-quality service

User-friendly online submission system

Fair and swift peer-review system

Efficient typesetting and proofreading procedure

Display of the result of downloads and visits, as well as the number of cited articles Maximum dissemination of your research work

Submit your manuscript at: http://papersubmission.scirp.org/

Or contact ojst@scirp.org 